\title{
Students, psychosocial problems and shame in neoliberal higher education
}

Wulf-Andersen, Trine Østergaard; Larsen, Lene

Published in:

Journal of Psycho-Social Studies

DOI:

$10.1332 / 147867320 \times 15986395598815$

Publication date:

2020

Document Version

Peer reviewed version

Citation for published version (APA):

Wulf-Andersen, T. Ø., \& Larsen, L. (2020). Students, psychosocial problems and shame in neoliberal higher education. Journal of Psycho-Social Studies, 13(3), 303-317.

https://doi.org/10.1332/147867320X15986395598815

\section{General rights}

Copyright and moral rights for the publications made accessible in the public portal are retained by the authors and/or other copyright owners and it is a condition of accessing publications that users recognise and abide by the legal requirements associated with these rights.

- Users may download and print one copy of any publication from the public portal for the purpose of private study or research.

- You may not further distribute the material or use it for any profit-making activity or commercial gain.

- You may freely distribute the URL identifying the publication in the public portal.

Take down policy

If you believe that this document breaches copyright please contact rucforsk@kb.dk providing details, and we will remove access to the work immediately and investigate your claim. 


\title{
Journal of Psychosocial Studies
}

Theme: Psychosocial approaches to neoliberal politics, institutional settings and welfare practices.

\section{Students, psychosocial problems and shame in neoliberal higher education}

Trine Wulf-Andersen and Lene Larsen

\begin{abstract}
In this article, we point to mental health as a new sorting mechanism in higher education (HE), working through categories informed by psychological and psychiatric knowledge, which currently permeates the field of education. The significant increase in young people, e.g. students in HE, with mental health problems such as stress, anxiety and depression seems to be a general development in Western countries over the past decade. The focus on mental health sets a broad range of wellbeing discussions and initiatives in terms of mental illness and/or psychiatric diagnoses, rather than in in casu learning, pedagogy, or participation and inequalities in education. This directs attention to particular kinds of students rather than to educational relations, cultures and contexts. Against this background, we set out to discuss how certain categorizations and understandings of students' well-being and everyday problems, inspired by the psy-sciences, intertwine with neoliberal traits in educational institutions, and come to mediate students' emotional experience of and coping with psychosocial problems and their participation in HE.
\end{abstract}

\section{Introduction}

The purpose of this article is to show how different categorizations and understandings of students with psychosocial problems intertwine with neoliberally informed practices in the field of education and influence students' subjective identity processes, participation and belonging in higher education (HE).

Neoliberal tenets in the global field of education incite higher education institutions (HEIs) to engage in academic capitalism: market-like behaviours with an overall focus on competition, measurement, assessment and employability (Saunders 2007, Allen et al. 2013, Burke 2017). Several authors have discussed what these neoliberal traits in education mean for social justice and inclusion, and for the understandings of what societal role HE is to have (e.g. Connell 2012, Bhopal \& Shain 2014, Bowker \& Levine 2017).

Neoliberal paradigms influence and change not only institutions but also student lives in several ways. Economic conditions for students to participate in HE are under pressure due to decreased state support and lack of (affordable) housing, followed by increased student debt (Fisher 2009). As Saunders (2007) argues, we should be attentive towards inequality emanating from neoliberalism as a hegemonic project in a Gramscian sense, and not only towards the links between neoliberalism and economic inequalities in HE. Neoliberal imprints like widespread acceleration, performance requirements, highly competitive study cultures and the individualization of responsibility are at work in daily interactions and institutionalized in patterns 
of privilege and disadvantage in today's HEls (Burke 2017, Sarauw \& Madsen 2016, Saunders 2007, Rosa 2013, Rose 2019). We agree with Connell (2012), for example, who argues for thorough analysis of such institutionalized patterns and how mechanisms of inequality change historically (Connell 2012: 681).

\section{Mental health and students of value in neoliberal higher education}

In this article, we point to mental health as a new sorting mechanism in $\mathrm{HE}$, working through categories informed by psychological and psychiatric knowledge, which currently permeates the field of education (Rose 2019). The significant increase in young people with mental health problems such as stress, anxiety and depression seems to be a general development in Western countries over the past decade. International research documents that about every third student in HE suffers from psychosocial difficulties (e.g. Kolouh-Söderlund et al 2016; Ibrahim et al 2013; Storrie et al 2010).

The focus on mental health prompts attention to a particular group of students in HE.

Undoubtedly, one desired result is the positive accommodation of more students with mental health problems or disabilities and the support of general student well-being in HE (Thomas 2012). But the increased focus on mental health problems, and the need of a language to speak about them, as Rose (2019) points out, simultaneously sets a broad range of well-being discussions and initiatives in terms of mental illness and/or psychiatric diagnoses, rather than in in casu learning, pedagogy, or participation and inequalities in education. This directs attention to particular kinds of students (Hacking 2006), and the valuation of them (Skeggs 2011), rather than to educational relations, cultures and contexts. This coincides with HE going through "an identity crisis of its own" related to universities' purpose, organization and understandings of learning and community in the light of the competitive market and the interests of diverse groups of students and stakeholders (Bowker \& Levine 2017).

In Danish $\mathrm{HE}$, neoliberal transformations have notably led to a focus on study intensity and faster completion, an evaluation culture emphasizing individual performance, and an intense focus on dimensioning and directing $\mathrm{HE}$ at employability and performative cultures on the labour market (Rasmussen 2020). Reforms construe students as rational, informed consumers of education, capable of and responsible for choosing the education, which is her/his ideal match, and for managing and optimizing her/his everyday study efforts, e.g. through the use of detailed timetables and models for study activity (Frederiksen \& Sarauw 2020). Thus, students who for whatever reason do not keep up to speed or follow linear paths through HE stands out as problematic.

Broader analyses in our own research show how students compare themselves to a category of the '(normal) student of HE' thought to be well and robust, accomplished and accustomed to education; able to work independently, complete education and be employed. This means that students evaluate themselves in relation to a political-cultural category of 'the good student', 
institutionalized as an implied student in HE (Ulriksen 2009). Categories of 'young people with mental health problems' are equally institutionalized and influential: thought of as vulnerable and (chronically) ill, academically weak and not familiar with educational settings, in demand of support, at high risk of dropping out or exceeding completion time, and not likely to be employed. Dichotomous categorizations hold the risk that students experiencing psychosocial problems will be understood, by fellow students, staff and by themselves, as being deficient of value (Skeggs 2011) and being incompatible with 'the good student' and therefore not belonging in HE (Larsen et al 2020).

Against this background, we set out to discuss how certain categorizations and understandings of students' well-being and everyday problems, inspired by the psy-sciences (Rose 2019), intertwine with neoliberal traits in educational institutions, and come to mediate students' experience of and coping with psychosocial problems and their participation in HE. For analytical purposes, we prefer to use the term 'psychosocial problems' (rather than the empirical category of 'mental health problems' or 'mental illness') in order to refer, from a critical, sociological perspective, to situations where societal and institutional dynamics intertwine with subjective feelings and identity processes, and shape the everyday life experience of ill-being.

The article unpicks how students understand and process experiences of shame and unworthiness, related to the particular problems or situations of ill-being they live through and to the particular educational settings in which they participate. The starting point of the article is the empirical observation that the very categorization of students' problems as 'mental health problems' seems to contribute to students' experience of shame in HE settings. Theoretically, the concept of shame is suited to bring attention to how neoliberal values work their way into daily practices, representations and understandings at universities, as vehicles of social positioning and exclusion of particular students; and at the same time seep into some students' understanding of themselves as less worthy students (Frost 2016; Loveday 2016).

Our psychosocial contribution, thus, is to explore, from a student everyday-life perspective, how students relate to internally contradictory and divergent categorizations of their problems. We analyse how students take on or work to resist these categorizations, how they are affected by social valuation practices and try to orient in relation to them. Through this analysis, we aim to comment on the educational context, seeing experiences of shame as indicators or 'symptoms of inequality' (Loveday 2016).

\section{The Student Life Project}

The empirical basis of the article is an ongoing qualitative research project following students with psychosocial problems in HE in Denmark, the Student Life Project (2018-21).

In Denmark, the strong welfare state provides conditions for students which, compared to many other countries, are in general quite favourable - and to some extent protective against economic inequalities stemming from neoliberal capitalism. This is in regard to, for instance, access to HE, 
general public support for education and entitlement to special support for students with mental (or physical) disabilities. Even so, the number of young people reported ill due to stress, anxiety, depression, etc. has increased significantly in Denmark too, as has the number of students with mental health problems in HE. Survey data from the Ministry of Higher Education and Science show that $18 \%$ of all Danish students always or often suffer from severe stress symptoms (UFM 2019), and the number of students of HE receiving special student support increased dramatically in the years 2010-2018.

In this context, the Student Life Project represents a research interest in how HE can accommodate and ensure supportive education and teaching environments for a diversity of students, as well as specifically support students in coping with psychosocial problems. Theoretically, the project builds on critical educational research and critical research into mental health. The project is funded by the Velux Foundations, Roskilde University and Aalborg University, and is the first and largest of its kind in the Danish context.

The research team of six researchers currently follows 47 students from different study programmes and educational institutions in Danish HE. Students join the project reflecting on posters and digital posts. The only criteria for inclusion are that the student experiences some kind of problem with well-being and is a student of $\mathrm{HE}$ at the time of inclusion. We continue to follow students who complete their study, leave the study, are on sick leave, etc.

Central to the methodological design are several rounds of in-depth interviewing ${ }^{1}$. We meet each student for two or three ethnographically inspired interviews over a period of 6-15 months. We meet where the student feels comfortable, and each interview lasts between one and four hours. The interviews explore the student's specific experience of problems and educational contexts (current and previous), and what the student's broader everyday life, social network and selfunderstanding look like.

Furthermore, we ask students to point out a place of importance to them and visit the place with them. We have walked-and-talked our way through numerous educational settings, but have also visited places to take a walk, favourite cafés, students' apartments or rooms etc., sometimes meeting the students' friends, partners, parents, children or dogs. These visits widen and deepen the field of attention and bring sensuous experience to the fore.

Taken together, the data is rich with 'thick descriptions' of students' experience of struggles and successes, inclusion and exclusion, and of the arenas and strategies for participation in which students' social practices take place. Transcripts, pictures and field notes from interviews and visits, are objects for collective analysis by the research team.

For the analysis in this article, we include empirical examples from 14 interviews and visits, all conducted by the authors, with four women in their mid-20s to early 30s. We selected this material for the purpose of the analysis of how students' experience shame, inequality and

\footnotetext{
${ }^{1}$ Supplementary design elements are three (annual) workshops and small-scale practice experiments with student counsellors from HE Institutions, private counselling units and NGOs - and, beginning in the autumn of 2020, a line of discussion meetings on student well-being and belonging at HE Institutions with the common title 'It's Cool to Care'.
} 
exclusion in HE. However, the larger body of data and the analytic work done by the research team so far also inform and validate the present analysis².

\section{Shame through the lenses of categories and person value}

Shame is defined in the dictionary as 'an intense crisis response to inadequacy or misbehavior' (Scheff 2014: 130), i.e. a certain kind of emotion. We understand emotion in a symbolic interactionist framework, emphasizing cultural and situational contexts and seeing self-conception and identity as dynamics central to emotions (Turner \& Stets, 2006). We are also inspired by feminist-anthropological conceptualizations of emotions as cultural-historical discourses on power, analysing emotions as "creative contributions that seek the resolution of cultural-historical paradoxes suffered by the individual" (Lutz 2014: 351) - e.g. depression as "associated with situational factors of powerlessness" (Lutz 2014:352).

Several recent publications on shame try to combine social science with different kinds of psychoanalytical theory in order to comprehend and conceptualize the simultaneously subjective and cultural sense of shame, and the way shame works as a complex social and reflexive feeling (Sedighimornani 2018). Scheff (2014), elaborating on theoretical insights from Goffman and Cooley's concept of intersubjectivity, the looking glass self, points to shame as an emotion which in particular signals the state of the relationship or bond between individual and society as secure or threatened, as connectedness or disconnect (Scheff 2014: 133). Frost (2016), too, points out that shame is experienced by the subject as a social emotion of feeling misrecognized, unworthy and disconnected or excluded from the community. She argues with Fraser that shame and misrecognition are consequences of institutionalized patterns of interpretation, denying the subject the status of full partner in social interaction (Frost 2016: 432). In this sense, misrecognition is not only intrapersonal or interpersonal but also closely linked to the structural powers and discourses that define subjects as unworthy. Frost emphasizes shame as a psychosocial term linking structural damage with relational and personal elements of well-being (Frost 2016) and argues that to be recognized and misrecognized always is a psychological state an internal damage - too. We need to be sensitive towards this in order to understand how experiences of shame 'can undermine agency and dis-empower the subject', and how this makes people struggle with both personal and professional identities (Frost 2016: 432).

In the following, we focus on the relation between the social and subjective levels. The analysis below will emphasize how structural relations, cultural and institutional codes and social dynamics

\footnotetext{
2 The fact that all students represented here are women mirrors that, in total, more women than men (35 female and 12 male students) have joined the project. Furthermore, in the research team, we are each responsible for contact with students from particular educational institutions, representing different academic profiles and study programmes - which are notoriously gendered. Thus, it might also account for the overrepresentation of women in our particular groups of students that we are both female researchers and they are predominantly students at a reform university and a welfare-oriented university college. For instance, one of our male colleagues in the research team, responsible for students from a traditional and a technical university, has more men in his group.
} 
are at work, in ways often invisible to the students affected, experiencing and processing inequality as shame. We focus on shame related to categorizing, and shame as played out in social valuing practices. These dimensions of shame are, in practice, closely knit together, however the analytical distinctions privilege different insights on how shame becomes an individualized symptom of inequality, threatening students' well-being and sense of belonging in HE.

Categorizing as stigmatization is a classic topic in the sociology of education. Bourdieu (1996), Bernstein (2001) and Domina (2017), for example, show how classifications reproduce the social affiliation of students without them being aware of it, and how this leads to sorting and exclusion processes, pointing out who counts as legitimate participants in education. This draws attention to how categories and categorizations inherently prompt inequalities, and how the educational system reproduces, produces, and structures social inequality in various ways through categorization of the students.

Several authors have emphasized how categorizations with diagnoses have a social impact in form of stigma and shame affecting the participation opportunities of those categorized (Becker 1963, Hacking 2006, Goffman 2009, Rose 2019). Recent literature also emphasize how young people and students with disabilities experience stigmatization particularly related to neoliberal trends (Thomas 2012, Soldatic \& Morgan 2017). Mental health is an example of the institutional reproduction of a powerful category, associated with stigma, which is introduced into a new field, i.e. as a relevant sorting category in the field of education. Here, it interacts and intersects with other classical and well known categories such as gender, class and ethnicity in particular experiences of shame and stigma, and it influences whether particular students are allocated to categories as 'students' or 'young people with mental health problems' (Larsen et al 2020). Allocation to particular formal categories does in some cases give access to help and support, but even in such cases, the use of mental health terminology and categories in a neoliberal context, as we shall see, simultaneously create new forms of social control, notably associated with shame in everyday experience.

Person value and deficit are slightly different concepts with which to address the question of shame in education, but working from a similar analytical angle as categorization. Several authors have elaborated on the inscription of lack and the naturalization of deficiency in the representation of particular students, taking working-class students as their case in point (Skeggs 1997; Jimenez \& Walkerdine 2011). Loveday (2016), for instance, explores shame as an important dimension of the lived experience of (staff and) students of working-class background in English $\mathrm{HEI}$. She adopts Skeggs' notion of 'person-value' in a feminist-Bourdieusian analysis of how systems of inscription, valuing, and institutionalization are reproduced by some groups at the expense of others through practices of exclusion (Loveday 2016: 1141). Loveday further theorizes shame by building on Wetherell's concept of 'affective practice', to emphasize how people actively engage in and are constituted through current and past practice. Loveday, like Scheff, argues that shame is often misrepresented as a property of individuals, and that it should rather be 
understood as a problem of society 'easily (...) turned into a deficiency of the self' (Loveday 2016: 1143).

Even if our analysis does not focus on social class, we find these insights to be important conceptualizations of students' differentiated opportunities to 'produce and publicly perform themselves as a subject of value' (Skeggs 2011:508). In the following analysis, we will show how students' experience of shame relate to categories and to person valuation practices and patterns of (mis)recognition in educational settings, and how this influences and is influenced by their wellbeing and their participation in $\mathrm{HE}$.

\section{Psychosocial problems as shameful categorizations}

In this first section, we show how students relate to the categories of 'student' and 'mental illness', and how being categorized as a person with mental health problems is associated with shame. We made the observation that the very categories of 'student' and 'mental health problems', even in a broad sense, seem to collide or be mutually exclusive. To many students in our project, the category of 'student' seems close to the category of 'normal young person', shaping students' expectations to themselves and everyday life as a student. On entering HE, Alicia, a 30-year-old student of Social Work, had 'picture-perfect' ideas of 'who l'd like to be'. She says:

In our society, there's so much focus on getting an education and getting on with it, and if you do it quickly, it is as though you score more points or something. So, in some corner of the subconscious, there's a realisation that it must be all wrong if I can't complete a study programme, like everyone else can.

To 30-year-old Dea, similar images of particular interests, abilities and work routines accompanied her idea of how to be a proper 'student' of HE, in her case in English. She describes 'this ambition of how my week should be':

It's a case of me diligently studying 7-8 hours a day, going to bed early so I can feel refreshed and be well-rested for the next day; and it's not...there's also allocated time to have a good time, so it's not entirely obligations all the time, but it is that sense of having to study 7-8 hours a day, that's what one ought to be doing. And that is just not always possible.

Many students work long hours, considering this an 'ought-to-do' of study life. But 'ought-to-dos' go beyond strict study activities. For Dea, reading the newspaper meant being the right kind of person, well-oriented about the ways of the world:

It became one of those 'ought-to-do' items: I should read my newspaper. And actually, I realised at one point that I couldn't be bothered to read that newspaper - and then I cancelled the subscription. Because it was an 'ought-to-do' and it was like: 'I'm paying for this newspaper, so I want to know about what's going on in the world and I would like to read in- 
depth journalism and so on - I should read my newspaper. And so I did, I forced myself to read that bloody newspaper - it was completely absurd.

Some students report being overwhelmed with 'ought-to-dos'. During the first months of her master's programme, Molly, a 30-year-old student of International Business, began to feel stressed, which developed into anxiety. At first, she did not identify her feelings as anxiety, but got scared:

I know that I am not going to die, and I am aware to some extent that what is going on right now is psychological, so I had a bit of trouble categorising what this was, that is, whether it was just that...that I was, I suppose, I thought that I was lazy

Molly debates with herself whether she is lazy or 'something psychic is going on', and she is looking for a category within which to place her experience. After lying in bed for two months eating candy and watching Netflix, she realizes that she needs help and contacts a doctor:

So I started taking antidepressants...yeah, so that was a fairly rough spring, because I felt that I should, well, I didn't want the others at my student job to know that I was feeling badly or anything; I felt that I had always been seen in a certain light in that place and I wanted to carry on being seen in that light and keep getting that positive feedback.

Molly struggles with seeing herself as 'someone who had mental health problems', and therefore is reluctant to get help. She tries to keep her ill-being, now treated as a mental illness, a secret from her colleagues on her student job, to not be seen in a 'bad light' or be categorized in a potentially stigmatizing way.

Unlike Molly, some of the students tend to identify closely with their diagnostic category and be quite open about it. Signe, a 26-year-old student of Physiotherapy, is one such student:

I tend to say that I am bipolar, it's not something I have, it's something that is in my personality. But it's not something I should misuse, but on the other hand, it can be quite nice sometimes to play that card, because then there's not so much to discuss, and it's not just me being weird, or bad in any sense, I have something, you know, physical, which makes certain things challenging for me. And it's as though because I have that, then I can be taken seriously and I am listened to...

The diagnostic category provides Signe with a vocabulary for developing an understanding of herself, everyday-life strategies and access to certain forms of support, e.g. a psychiatrist, a psychiatric nurse and a student counsellor. They all give Signe a 'professional validation' that she is 'not just lazy, and not just stupid, and I wasn't just nothing - instead there was a hormone in my brain that wasn't functioning as it should', and that studying is hard for students with 'extra things' in particular. This helps Signe at times when 'it feels a bit like a mountain, and I just don't have the right equipment'. 
Nonetheless, Signe too has worries as to how others might interpret and categorize her and her 'extra thing'. There is a fine line between when 'playing the card' seems legitimate and when it is 'misuse'. This is a general concern for students related to receiving support: it is somehow associated with cheating. To Signe, 'it's not that there's anything wrong with asking for help', however, she and reportedly her fellow students all have the tendency to think that 'this will pass that is, it might just be me being a bit of a whiner, and everyone else also thinks this assignment is difficult', making students 'disregarding it' too long before seeking help. Other students, however, do tell us about explicit stigmatizing comments, pointing to, e.g., extra time, assistance or aids as cheating. Signe usually comes across as a competent, ambitious student. Asking for help is a dilemma, because she worries that it will undermine how those around her take her seriously as a learner and an academic. She says:

When I am feeling well, like during my last internship here, I told my supervisor about it and she was like: 'I would never have guessed'. Because she's seen me function. But during my previous internship when I felt really bad, my supervisor was just...well, I could sense after I got better again later, that she had set the bar very low for me, she didn't really have high expectations of me.

Since the supervisor's expectations to her were 'too low', it put Signe in a 'weak role', made the internship 'a bit boring', and 'didn't bring me forward at all'. This makes her worry for her learning curve while in education and, furthermore, for her future as a professional if she is seen as someone who cannot keep up or 'adjust to the workplace'. Signe and Molly both distinguish between 'mentally ill', which holds some kind of legitimacy, and more problematic categories of 'lazy', 'stupid' or 'weak' students as opposed to ambitious, competent, and strong students, better 'equipped' to deal with problems.

Students on an everyday basis orient themselves and their study routines towards working long and hard, presenting themselves as capable, and completing what they started on time, compliant to neoliberal HE. The quotes above are examples, too, of the dilemmas students experience when they find it hard to live up to the neoliberally informed category of 'the good/normal student'. Students come to doubt themselves as worthy or legitimate participants in HE, comparing themselves to the categorical figure of 'the good/normal student'. The constant comparative and competitive evaluation of students seep into students' monitoring and evaluating themselves, as well as into teachers' and supervisors' assessments. Defining 'people with mental health problems' and 'normal people/students' as separate categories makes it difficult for students to orientate and formulate identity positions of simultaneous ill-being and being normal competent students. Molly and Signe, for instance, are both struggling with dilemmas of if and how it is possible to disclose problems and still be considered a worthy student in HE? Is it possible to maintain an identity as a good or normal student in HE if you need help and support? If you in fact receive help and support, how is it possible to measure and recognize your performance in comparison with others? Dilemmas like these stem from dichotomous categories and neoliberal policy, and carry experiences of shame and of being unworthy. One specific way that this affects 
students is that they often refrain from seeking help and support (Storrie et al. 2010). Many students in our project report that they hid or dismissed problems for a long time before acknowledging them or disclosing them to others. As we shall see below, categories and the dilemmas associated with them also affect students as they work through social practices and interactions among students.

\section{Valuation and exclusion in social practice}

In this section, we present examples of how neoliberal trends permeate student interactions and valuations of each other and themselves. We focus on how students engage in or withdraw from local study cultures and inclusion/exclusion practices and experience these practices as continual processes of competitive valuation and self-valuation. Our primary focus will be on how students relate valuation to personal deficits or contextual inequalities, and where students experience shame in 'going against each other' or 'going against themselves'.

When Molly approaches her master's thesis, problems arise. She wants to work with another student, which is an option in her study programme. However, their professor recommends all students write their thesis alone, to ensure their chances of writing a PhD. After this, everybody wants to write his/her thesis alone, and Molly feels lost. Writing alone is a big challenge for her, and she becomes delayed. After a period, doing fieldwork in another country, she moves in with two other students, writing on their theses as well. They suggest that they all sit together and write, as mutual support, but Molly dodges:

We could have...sat together and done the writing and my friend did offer to do that actually. But honestly, I think it just started preying on my mind even more living with these two, who were doing what I couldn't, what I couldn't seem to accomplish.

Rather than seizing the opportunity for support, the flatmates' offer triggers Molly's bad conscience and low self-esteem. Molly is ashamed of her inability to perform the way she thinks she should, not finding herself able to write on her own. Maybe similar feelings would have arisen for Molly had she in fact written her thesis with a fellow student. However, the dismantling of cowriting as a legitimate way of organizing thesis work relates to a professor's elitist framing of all students as future PhD students, and as such, to competitive social practices in the educational setting determining what ambitions and work routines proper students are supposed to have. In the end, this is significant for Molly's experience of shame and her disinclination to make use of the offer to write together.

Molly's feeling of shame extends and affects how she relates to friends. Being ambivalent about the categorization as 'mentally ill', she tries to keep the anxiety a secret and withdraws from social life:

There, in a way, I felt that I was walking around with a secret (...) or something I had to navigate my social life around, um, I suppose mostly to avoid social events. But when I did interact, then, then I tried to sort of, I didn't feel like I had a lot to contribute, but I tried to be 
the sort of person who listens and then just listen to what the others (laughs) were talking about, if we were in a group

Molly's more general sense of not having 'much to offer' shows how a student's reception of one, maybe rash, comment from a professor can sometimes grow into a global sense of personal deficit. We should not dismiss such incidences as one student's (over)reaction to an unfortunate remark, even if this process to a large extent takes place in a private or individual domain. We see numerous examples where equivalent valuation processes play out in rather more manifest exclusionary dynamics, e.g. among students.

Alicia's first experience with HE, before coming to Social Work, was at Law School 10 years ago, a time full of 'suffering through education', she says, 'lots of guilt and shame'. A lawyer at her workplace encouraged Alicia to apply, and she was flattered and proud by the suggestion, and later by the fact that she got in. But from early on, Alicia seems to be alone. For various reasons, all the other students in Alicia's designated study group dropped out very early in the term. Where other students had support from the group in remembering instructions, registering for exams, surveying the curriculum and so forth, Alicia felt she was hanging by a thread, having more and more difficulties managing. She says:

After a while, I became more and more anxious about showing up, because I was imagining the others thinking - What the hell is she doing here, that idiot, why hasn't she given up yet? Um, and then I just sort of ended up staying home around the clock, without having anything to do, other than sitting and reading those chapters, over and over and over again, and then turning up to the exam and failing everything on the first try, every time.

The atmosphere at Law School was very competitive and prestige oriented and did not invite questions from students even in smaller classes. Students looked down upon others who had no student job in a law firm or good grades. Appearances, wearing expensive clothes, bags and pearls and the like was very important. Alicia describes an incident from the lecture hall, when a student asked if she could sit next to a fellow student, but ended up sitting on the floor, because the other student 'wasn't prepared to move her Gucci bag from the seat, because the floor was sticky'. To Alicia, student talk of other students was harsh rather than supportive:

What was talked about instead was more along the lines of - 'This is completely ridiculous, I mean, why is he even here, if he can't... Just think of all the other students who wanted to get in to this course' - And, you know, in a way it started to be a bit judgemental. Um, and I remember being told that there was a guy from my, from my own class who said that about me, um, to a mutual friend. Um... and like, that was just, it caused even more shame in me and, and it was a total downer, and I started to feel even more embarrassed about showing up

Alicia felt continually worse with anxiety, stress, sleeping and eating problems. Nevertheless, she held a strong obligation to stay, to complete her education, and could not 'just give up'. She hung on to Law School through more than three years, while her family became increasingly worried 
and eventually urged her to quit. Not until a doctor more or less by chance identified a substantial weight loss did Alicia leave Law School and got help.

Alicia's experience from Law School is a good example of a student 'feeling lost' in a study environment highly attuned to capitalist, competitive, neoliberal values. While involved in this culture, the interpretation that problems are due to her shortcomings or deficits seeps into her, and she turns against herself (cf. Burke 2017). Shame becomes a thorough bodily experience for Alicia. Importantly, controlling her weight becomes her way of complying with a culture of looks and control, and even 10 years later, remembering Law School in the interview makes her feel physically sick. Alicia describes the immediate link between structural damage, social relations and personal elements of well-being (Frost 2016):

I've had the most extreme, most malicious inferiority complexes from seeing how all my old school friends, right after graduating with their Masters, they just sprouted wings and took off; and I was really happy for them, but wow did I feel wrong, and like I don't belong in this society (...) (voice cracks). (...) Everyone is busy with their own things, and I'm just walking around in this bubble and thinking, like, I have no purpose.

With no sense of direction or purpose, Alicia in a sense experiences a loss of her right to participation in or membership of society, which in neoliberal governance to a high degree depends on educational level and labour-market participation. Shame is the emotion term Alicia presents as a collective name to a range of feelings of being wrong, unworthy, without purpose, inferior etc. Shame marks Alicia's (re)orientation in educational relations, cultures and contexts imprinted and governed by neoliberal trends. Shame becomes not just a responsive reaction in the attempt to adapt to demands on efficiency and performativity, but an (inter)subjective experience shaping both Alicia's identity and self-understanding and the collective identity and cultural figures of HE, of Law School.

Institutional traditions and values in different HE settings shape the social valuation practices in the above examples, thereby facilitating particular conditions for students' relations. Shame relates to valuation practices, which sometimes play out very explicitly and tangibly in exclusionary dynamics among students turning against each other (cf. Burke 2017), like at Alicia's Law school. The (inadvertent) role of staff in preparing for particular cultures of dos/don'ts, and who is in/out, seems very important, too. However, valuation also works through students' own regulation of themselves, when students turn against themselves, like in Molly's choosing not to work alongside fellow students. Both kinds of valuation and exclusion mechanisms affect students in the form of shame, seen by students as glaring personal deficits rather than 'disorders' of the context. Inequality and exclusion working through shame is powerful this way. It makes students hide and blame themselves. It preys on their sense of being a worthy or even possible participant, not only in $\mathrm{HE}$, but in the world in a broad sense as well. In this way, shame discourages these students from expecting or believing in their own worthiness, belonging and community, and from thinking 
that they can have a place in society. Up to a point, where a student rather than a Gucci bag sits on the sticky floor.

\section{Shame and the experience of neoliberal HE}

Alicia, Dea, Molly and Signe all struggle to be legitimate participants in their student communities. They struggle for recognition as students, as friends, as future academics, ultimately to enter the bigger picture as members of society, having completed an education and contributing by holding a job. The empirical examples above show students' experience of being categorized and (de)valuated, and how the emotional experience of shame affect students and influence their selfimage and social relationships.

Shame is an analytical focus suited to explore not only the subjective experience but also the context surrounding students' responses to problems of student life. Here we have shown how the categories of 'the good/normal student' and 'mental health problems' directs students' (re)orientating themselves in $\mathrm{HE}$, relating to the categories with acceptance, resistance and/or rejection in attempts not to be excluded from particular local study cultures. Adopting distinct categories as 'mentally ill' as opposed to 'normal', they seem to reproduce and activate binary codes developed outside the educational system in the valuation processes within HE communities. This is an example of how categories informed by psychological and psychiatric knowledge influence the field of education, blurring the assessment of students' academic ability. This happens when political and structural dimensions of the educational context saturate social valuation practices, shape ideals and norms of what legitimate students should be and do, and identifies, naturalizes, and deals with inequality as particular students' deficits or individual illnesses. Such processes reduce or hide the experience of shame as an individual issue - a personal lack of confidence or academic stamina. Such processes, too, shape both these specific students and the individual and collective others of HE as entities in a certain way.

In the analysis of shame in $\mathrm{HE}$, we also see how any sharp distinctions between shame as a subjective experience and as social positioning processes dissolve. Through the lenses of categorizations and shame in social practice, it is possible to shed light on how structural and political relations make some students more prone to experiencing shame than others (Sedighimornani 2018). How neoliberal trends turn into processes of self-criticism and social exclusion is something we should explore as indicators or symptoms of inequality in HE. For this, we need an understanding of shame/shaming as the simultaneous process of subjective emotion and social positioning and critical perspectives crucial to understand how HE settings produce, reproduce, and institutionalize categories and categorizations of inequality. We need also to understand, empirically and theoretically, how structural and institutional inequalities translate into emotion at an unconscious and pervasive level, into feelings of shame, alienation, etc. (Frost 2016: 437). This is necessary to the analysis and understanding of how neoliberal dynamics are at 
work not only in terms of economy but also as a hegemonic project related to identity processes (Saunders 2007).

We have focused on shame as the result of neoliberally informed cultural and social practices, of students 'being affected' in everyday interactions in educational settings, and thus as a symptom of inequality. With its reflexive nature, students often experience shame in relation to the naturalization and individualization of deficits as 'an intense feeling of the subject "being against itself"' (Burke 2017: 435). Our point in this article has been to direct attention to educational contexts and cultures with a neoliberal orientation, because they can intensify inclinations towards assessment and the inscription of value or lack of value in student interaction. Luckily, our empirical material also contains examples of students with psychosocial problems meeting more open study cultures, where students are more likely to maintain self-confidence, and experience the strong, recuperative feeling of being recognized as a desired participant. Analysing how shame and inequality shape individual and collective identities in neoliberal $\mathrm{HE}$, we have sought to conduct critique of both privatisation of emotions and the social structure producing this.

\section{References:}

Allen, K, Quinn, J. Hollingworth , S. \& Rose, A. (2013). Becoming employable students and 'ideal' creative workers: exclusion and inequality in HE work placements, British Journal of Sociology of Education, 34:3, 431-452, DOI: 10.1080/01425692.2012.714249

Becker, H. (1963). Outsiders: Studies in the Sociology of Deviance. New York: Free Press.

Bernstein, B. (2001). Pædagogiske koder og deres praksismodaliteter. I: Chouliaraki, L. og Bayer, M. (2001). Basil Bernstein, Pædagogik, diskurs og magt. Akademisk forlag, s. 69-93.

Bhopal, K \& Shain, F (2014) Educational inclusion: towards a social justice agenda? British Journal of Sociology of Education, 35:5, 645-649, DOI: 10.1080/01425692.2014.938937

Bourdieu, P. (1996). The state nobility: Elite schools in the field of power. Cambridge: Polity.

Bowker, M. H. \& Levine, D.P. (2018). A Dangerous Place to be. Identity, Conflict, and Trauma in Higher Education. London: Karnac Books Ltd.

Burke, P. J. (2017). Difference in HE pedagogies: gender, emotion and shame, Gender and Education, 29:4, 430-444, DOI: 10.1080/09540253.2017.1308471

Connell, R. (2012) Just education, Journal of Education Policy, 27:5, 681-683, DOI:

10.1080/02680939.2012.710022

Domina, T., Penner, A., Penner E. (2017). Categorical Inequality: Schools as sorting machines. Annuel Review of Sociology, 43, 311-30.

Fisher, M. (2009). Capitalist Realism: Is There No Alternative? (1.). e-book: Zero Books. 
Frederiksen, J.T. and Sarauw, L.L. (2020): Universitetet som plan B - studietvivl som copingstrategi blandt universitetsstuderende. Dansk Pædagogisk Tidsskrift nr. 1. s. 23-34.

Frost, L. (2016): Exploring the concepts of recognition and shame for social work. Journal of Social Work Practice, 2016 Vol. 30, No. 4, 431-446, http:/dx.doi.org/10.1080/02650533.2015.1132689

Goffman, E. (2009. Stigma. Om afvigerens sociale identitet. København: Samfundslitteratur.

Hacking, I. (2006). Making up people. The London Review of Books, 28(16): 23-26.

Ibrahim, A. K., Kelly, S. J., Adams, C. E., \& Glazebrook, C. (2013). A systematic review of studies of depression prevalence in university students. Journal of Psychiatric Research, 47(3), 391-400. http://doi.org/10.1016/j.jpsychires.2012.11.015

Jimenez, L. \& Walkerdine, V. (2011). A psychosocial approach to shame, embarrassment and melancholia amongst unemployed young men and their fathers. Gender and Education, 23 (2): 185-199.

Kolouh-Söderlund, L. \& Lagerkranz, H. (2016). Mental Health among Young People. Nordic Centre for welfare and Social Issues.

Larsen, L, Weber S.S., Wulf-Andersen, T. (2020). Asynkronitet og sortering i et accelereret uddannelsessystem. Dansk Pædagogisk Tidsskrift nr. 1. s. 35-49.

Loveday, Vik (2016). Embodying Deficiency Through 'Affective Practice': Shame, Relationality, and the Lived Experience of Social Class and Gender in HE. Sociology, 50 (6): 1140-1155

Rasmussen, P. (2020). Universiteterne på vej - hvorhen? Dansk Pædagogisk Tidsskrift nr. 1. s. 9-22.

Rosa, H. (2013). Social acceleration: a new theory of modernity. New York: Columbia University Press.

Rose, N. (2019). Our Psychiatric Future (1.). Cambridge: Polity Press.

Sarauw, L. L., \& Madsen, S. R. (2016). Studerende i en fremdriftstid: Prioriteter, valg og dilemmaer set i lyset af fremdriftsreformen : Analyser og tal fra landsdækkende spørgeskemaunders $\varnothing$ gelse blandt 4.354 universitetsstuderende. DPU, Aarhus Universitet.

Saunders, D. (2007). The Impact of Neoliberalism on College Students, Journal of College and Character, 8:5, DOI: $10.2202 / 1940-1639.1620$

Scheff, T. (2014). The Ubiquity of Hidden Shame in Modernity. Cultural Sociology 2014, Vol. 8(2) 129-141

Sedighimornani, N. (2018). Shame and its features: Understanding of shame. European Journal of Social Sciences Studies, 3(3):75-107.

Skeggs, B. (1997). Formation of class and gender. Becoming respectable. London: Sage.

Skeggs, B. (2011). Imagining personhood differently: person value and autonomist working-class value practices. The Sociological Review, 59(3):496-513. 
Soldatic, K. \& Morgan, H. (2017). "The way you make me feel": Shame and the neoliberal governance of disability welfare subjectivities in Australia and the UK. IN. Louth, J. \& Potter, M. Edges of Identity (ed): The production of Neoliberal Identities. Chester: University of Chester Press. p. $106-133$.

Storrie, K., K. Ahern \& A. Tuckett. 2010. A systematic review: Students with mental health problems - A growing problem. International Journal of Nursing Practice 2010 16: 1-6

Thomas, L. 2012. Building Student Engagement and Belonging in HE at a Time of Change: Final Report from the What Works? Student Retention and Success Programme. London: HEFCE.

Uddannelses- og forskningsministeriet (2019). Stress og trivsel blandt studerende. København: Uddannelses- og forskningsministeriet.

Ulriksen, L. (2009). The implied student. Studies in HE, 34(5), 517-532. 